\title{
Australian Journal of

\section{Non-destructive measurement of canopy cover is an alternative to biomass sampling at anthesis to predict yield of canola-quality Brassica juncea}

\author{
Babu Ram Pandey ${ }^{1}$, Wayne A. Burton ${ }^{2}$, Phillip A. Salisbury ${ }^{1,3}$, Marc E. Nicolas ${ }^{1}$ \\ ${ }^{1}$ Faculty of Veterinary and Agricultural Sciences, University of Melbourne, VIC 3010, Australia \\ ${ }^{2}$ Seednet Australia, Grains Innovation Park, 110 Natimuk Road, Horsham, VIC 3400, Australia \\ ${ }^{3}$ AgriBio, Centre for AgriBioscience, Department of Economic Development, Jobs, Transport and Resources, \\ 5 Ring Road, Bundoora, Vic. 3083, Australia
}

\section{*Corresponding author: babu.pandey@ecodev.vic.gov.au}

\begin{abstract}
Biomass at anthesis is an important trait in predicting yield of Brassica oilseeds in environments where seed filling occurs in dry and warm conditions. This study aimed to compare the ability of non-destructive canopy cover measurements (Sunfleck ceptometer and digital photography) with direct biomass sampling at anthesis to predict the yield of canola-quality B. juncea (juncea canola) hybrids. Field experiments were conducted in the Victorian Mallee (226-248 mm annual rainfall) and the Wimmera (266-407 mm annual rainfall) regions from 2012 to 2014. Nineteen juncea canola genotypes were sown in the first year and 10 to 11 genotypes in the subsequent two years of field experiments. The experimental plots were laid out in a randomized complete block design with three replications. Days to 50\% flowering, canopy cover and biomass at 50\% flowering and seed yield were recorded. The study concluded that at low rainfall sites ( $<250 \mathrm{~mm}$ annual rainfall), the canopy cover measurements had consistent and significant positive relationships with biomass at anthesis $\left(r^{2}=0.43-0.61\right.$ in 2012 and $r^{2}=0.72$ in 2013) and seed yield $\left(r^{2}=0.25-0.41\right.$ in 2012 and $r^{2}=0.51$ in 2013). Canopy cover also showed a positive and significant relationship with early flowering $\left(r^{2}=0.52\right.$ in 2012 and $r^{2}=0.60$ in 2013$)$ at the relatively low rainfall site. These results suggest that non-destructive canopy cover measurement could replace direct biomass sampling at anthesis in prediction of yield of juncea canola hybrids in low rainfall environments.
\end{abstract}

Keywords: drought; juncea canola; hybrids; low rainfall environments; ceptometer; digital photography. Abbreviations: PAR_photosynthetically active radiation; LAI_leaf area index; LI_light interception; DGC_digital ground cover.

Introduction

Canola (Brassica napus L.) is an important component of crop rotations in Australia but it has limited success in low rainfall environments (Robertson et al., 2002). Brassica juncea (L.) Czern. is regarded as an alternative cereal break crop to B. napus in low rainfall environments because of its heat and drought tolerance relative to B. napus (Wright et al. 1995; Wright et al. 1996; Oram et al. 2005). Additional advantages of $B$. juncea compared to B. napus include better early vigour and ground cover, greater competitiveness with weeds (Beckie et al., 2008), blackleg (Leptosphaeria maculans) resistance (Burton et al., 2007), greater shatter tolerance (Burton et al., 1999) and better performance under late sown conditions (Hocking and Staper, 2001). B. juncea has also been reported to develop deeper roots in response to drought (Devi et al., 2014). B. juncea has traditionally been used as condiment mustard. However, cultivars with oil and meal quality equivalent to canola (juncea canola) have been bred after considerable time and effort (Rakow et al., 1995; Oram et al., 1999). Juncea canola was first released in Australia in 2007 (Burton et al. 2007) and has shown potential as an alternative oilseed crop for low rainfall environments like the Mallee (Burton, 2009; Haskins et al., 2009). However, it currently has low yield and requires yield improvement (Gan et al., 2007; Gunasekera et al., 2009). There are several reports of exploitable heterosis for seed yield in B. juncea (Pradhan et al., 1993; Mahto and Haider, 2004; Patel et al., 2010; Malviya et al., 2012) and hybrid juncea canola is being developed for this purpose by Seednet in Australia (Wayne Burton, pers. comm.).

To date, there is limited research on the performance of hybrid juncea canola in Australian low rainfall environments. Brassica oilseeds in Australia face progressive drought and high temperature during seed filling stages. Under such typical Mediterranean environments, biomass at anthesis is important for weed management and use of water reserves and is a major determinant of yield (Richards et al., 2001). Biomass production is positively associated with yield in canola (Taylor and Smith, 1992; Yasari et al., 2008). Drought reduces the yield of Brassica crops by reducing the traits related to biomass production (Gunasekera et al., 2006; Gunasekera et al., 2009). Plants take up nutrients and accumulate biomass at maximum rates during pre-anthesis growth stages (Malhi et al., 2007). Pre-anthesis biomass production is associated with post-anthesis growth (Tommey and Evans, 1992) and the number of flowers, pod density and potential seed number (Hebekotte, 1993; Faraji, 2010). In B. napus, a decline in seed yield with later sowing was associated with a reduction in total dry matter production and pre-anthesis growth (Si and Walton, 2004).

Development of early flowering cultivars with good early vigour and quick ground cover is therefore an important breeding objective for $B$. juncea in Mediterranean conditions. The most commonly used method to assess crop growth is direct biomass sampling per unit area. However, this method 
is not practical for repeated large scale measurements. The method consumes considerable time, labour and resources. Recently indirect and non-destructive optical methods based on canopy cover have been used. A ceptometer is used to measure canopy cover by measuring the proportion of incident light intercepted by the canopy. The ceptometer measures photosynthetically active radiation (PAR) at the top of the canopy and under the canopy, allowing the proportion of PAR intercepted by the canopy to be estimated. Armbrust (1990) found that the ceptometer was a fast, simple and accurate instrument to measure canopy cover of wheat, maize and soybean. The ceptometer has also been widely used in measurement of leaf area index (LAI) of crop and forest canopies. Canopy cover can also be measured by processing digital images of the canopy taken directly above the crop. Digital photography has been widely tested and proven as an accurate, easy and fast method to estimate canopy cover and LAI of several crops. Lee and Lee (2011) tested digital photographs for estimation of canopy cover of rice and concluded that measurement of canopy cover with digital photography was effective. The technique was also effective in estimation of canopy cover of wheat at vegetative stages and had strong correlations with LAI $\left(\mathrm{r}^{2}=0.88-0.97\right)$ (Pan et al., 2007). Similar accuracy of canopy cover measurement by digital photography has been reported for turf grass (Richardson et al., 2001) and forest trees (Guevara-Escobar et al., 2005). A close linear relationship between canopy cover in onion measured using photographs and LAI was observed with coefficient of determination of $84 \%$ (Corcoles et al., 2013). The indirect methods have been found to be quicker and consume considerably fewer resources than the direct biomass sampling.

These indirect methods can also be more accurate than biomass sampling because they allow more replication. There are a few reports on the use of indirect measurements to determine canopy cover in Brassica crops. Behrens and Diepenbrook (2006) used digital photographs to determine canopy cover and LAI in winter B. napus. Chakwizira et al. (2015) compared two methods of canopy cover estimation (Sunfleck ceptometer and digital photography) for forage brassicas (kale, rape, turnip and swede), cereals (barley and wheat) and white clover and concluded that the two methods could be used interchangeably to estimate canopy cover. However, comparison of the ability of non-destructive (indirect) measurements and direct biomass sampling to predict yield has not been studied in Brassica species. This research aims to compare the non-destructive methods of canopy cover measurement (Sunfleck ceptometer and digital photography) with direct biomass sampling at anthesis in prediction of seed yield of juncea canola under low rainfall environments.

\section{Results}

\section{Effect of location on canopy cover, biomass and seed yield}

Location had a significant effect on canopy cover (measured as light interception in 2012 and digital ground cover in 2013), biomass at anthesis and seed yield in 2012 and 2013 (Table 1). Beulah and Piangil had significantly lower seed yield than Horsham in 2012. However, Piangil (with higher post-anthesis rainfall) had significantly higher seed yield than Beulah. Beulah and Piangil had similar biomass at anthesis and light interception but significantly lower than Horsham. In 2013, seed yield at Beulah was significantly lower than at Horsham. However, biomass at anthesis and digital ground cover were significantly higher at Beulah than at Horsham. Despite more rainfall, Beulah had considerably lower seed yield and biomass at anthesis in 2013 than 2012. Similarly, Horsham had considerably lower seed yield, biomass at harvest and canopy cover (measured as digital ground cover) in 2013 than in 2012 and 2014.

\section{Effects of genotype, genotype $\times$ location and genotype $\times$} year on canopy cover, biomass and yield

Mixed ANOVA showed that genotype had significant interaction with year and location for seed yield, biomass at anthesis and harvest index. However, analysis was focused on experiments in individual years because only four genotypes were common across years.

Genotypic differences were significant for all the traits in all the experiments except that anthesis biomass was not significant in 2014. Effect of genotype $\times$ location interaction was significant for seed yield in 2012 and digital ground cover in 2013. There was only one experimental site in 2014.

\section{Relationship of seed yield with canopy cover and biomass at anthesis}

There was a significant positive relationship of seed yield with canopy cover and biomass at anthesis in the majority of years and locations (Table 2). The exception was that there was no significant relationship between these traits at Horsham in 2013 and 2014. The coefficients of determination $\left(\mathrm{r}^{2}\right)$ of regression of seed yield plotted against canopy cover and biomass at anthesis were higher at the sites with relatively lower seed yield and rainfall (Beulah and Piangil) than at the site with higher seed yield and rainfall (Horsham). At Beulah, the $r^{2}$ value of seed yield against canopy cover was slightly higher than the $r^{2}$ value of seed yield against biomass at anthesis in 2012 whereas the $\mathrm{r}^{2}$ value of seed yield against canopy cover was considerably higher than $\mathrm{r}^{2}$ of seed yield against biomass at anthesis in 2013. The $r^{2}$ values of seed yield against canopy cover and biomass at anthesis were similar at Piangil and Horsham in 2012. The $\mathrm{r}^{2}$ values of seed yield against light interception and digital ground cover were similar at Horsham in 2014.

\section{Relationship of canopy cover with biomass at anthesis and days to flowering}

Canopy cover and biomass at anthesis were strongly correlated in 2012 (Fig 1) and 2013 (Fig 2). Across locations, canopy cover explained 79 and $61 \%$ variation in biomass at anthesis in 2012 and 2013, respectively. The amount of variation explained was 61,43 and $60 \%$ at Beulah, Piangil and Horsham, respectively in 2012. In 2013, canopy cover explained considerably higher proportion of variation in biomass at anthesis at Beulah (72\%) than at Horsham (58\%). Canopy cover measurements had positive and significant relationships with biomass at anthesis at Horsham in 2014 (Fig 3). However, the relationships were weaker than in 2012 and 2013. Canopy cover measured as digital ground cover and light interception explained 29 and $28 \%$ variation in biomass at anthesis, respectively in 2014. Canopy cover had a significant negative relationship with number of days to flower at Beulah (Fig 4) while these traits did not show significant relationships at Horsham. At Beulah, the relationship was stronger in $2012\left(\mathrm{r}^{2}=0.60\right)$ than in 2013 $\left(\mathrm{r}^{2}=0.52\right)$.

\section{Discussion}

Rainfall and yield data showed that the Mallee sites were strongly affected by water deficit in 2012 and 2013 (Fig 5, Table 1). Of the two Mallee sites in 2012, Piangil had 
Table 1. Location means of traits measured from 2012 to 2014 . Means followed by same alphabet are not significantly different according to LSD at 0.05 level. * and ** denote significance at 0.05 and 0.01 levels, respectively.

\begin{tabular}{cccccc}
\hline Year & Location & $\begin{array}{c}\text { Seed yield } \\
\mathrm{Kg} / \mathrm{ha}\end{array}$ & Biomass at anthesis $\mathrm{g} / \mathrm{m}^{2}$ & Light interception \% & Digital ground cover \% \\
\hline 2012 & Beulah & $1125 \mathrm{c}$ & $270 \mathrm{~b}$ & $65 \mathrm{~b}$ & - \\
& Piangil & $1686 \mathrm{~b}$ & $287 \mathrm{~b}$ & $64 \mathrm{~b}$ & - \\
& Horsham & $2389 \mathrm{a}$ & $464 \mathrm{a}$ & $94 \mathrm{a}$ & - \\
\multirow{2}{*}{2013} & Location & $* *$ & $* *$ & - & - \\
& Beulah & 352 & 197 & - & 53 \\
& Horsham & 803 & 142 & - & $* *$ \\
2014 & Location & $*$ & $* *$ & 80 & 77 \\
\hline
\end{tabular}

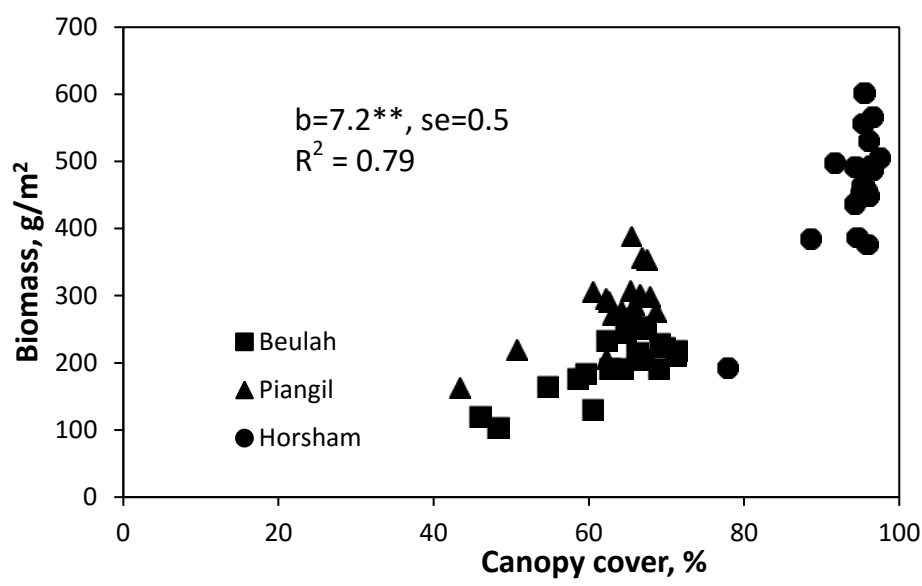

Fig 1. Correlation between canopy cover and biomass at anthesis of juncea canola hybrids at Beulah, Piangil and Horsham in 2012.* and ** indicate significance at 0.05 and 0.01 level of significance, respectively.

Table 2. Coefficients of linear regression (b) and coefficients of determination $\left(\mathrm{r}^{2}\right)$ values for seed yield (kg/ha) plotted against percent canopy cover (measured as light interception in 2012, as digital ground cover in 2013 and as both in 2014) and biomas s at anthesis of juncea canola genotypes in field.

\begin{tabular}{|c|c|c|c|c|c|c|c|}
\hline \multirow[t]{2}{*}{ Location } & \multirow[t]{2}{*}{ Year } & \multirow{2}{*}{$\begin{array}{l}\text { Light interception } \\
\% \\
\mathrm{~b}( \pm \text { s.e. })\end{array}$} & \multirow[b]{2}{*}{$\mathrm{r}^{2}$} & \multicolumn{2}{|c|}{$\begin{array}{l}\text { Digital ground cover } \\
\%\end{array}$} & \multicolumn{2}{|c|}{$\begin{array}{l}\text { Biomass at anthesis } \\
\mathrm{g} / \mathrm{m}^{2}\end{array}$} \\
\hline & & & & $\mathrm{b}( \pm$ s.e. $)$ & $\mathrm{r}^{2}$ & $\mathrm{~b}( \pm$ s.e. $)$ & $\mathrm{r}^{2}$ \\
\hline Beulah & 2012 & $16.6^{* * \pm 2.8}$ & 0.41 & - & - & $2.8 * * \pm 0.5$ & 0.36 \\
\hline Piangil & 2012 & $26.9 * * \pm 8.6$ & 0.25 & - & - & $4.8 * * \pm 0.9$ & 0.27 \\
\hline Horsham & 2012 & $18.8 * \pm 7.4$ & 0.10 & - & - & $0.9 * * \pm 0.3$ & 0.13 \\
\hline Beulah & 2013 & - & - & $15.1 * * \pm 3.4$ & 0.51 & $1.9 * * \pm 0.6$ & 0.32 \\
\hline Horsham & 2013 & - & - & $9.0 * \pm 3.2$ & 0.32 & $0.9 \mathrm{~ns} \pm 0.8$ & 0.09 \\
\hline Horsham & 2014 & $21.3 * \pm 7.8$ & 0.35 & $23.5 * \pm 9.4$ & 0.31 & $0.9 \mathrm{~ns} \pm 1.4$ & 0.02 \\
\hline
\end{tabular}

$*$ and $* *$ indicate significance at 0.05 and 0.01 level of significance, respectively. ns, not significant.

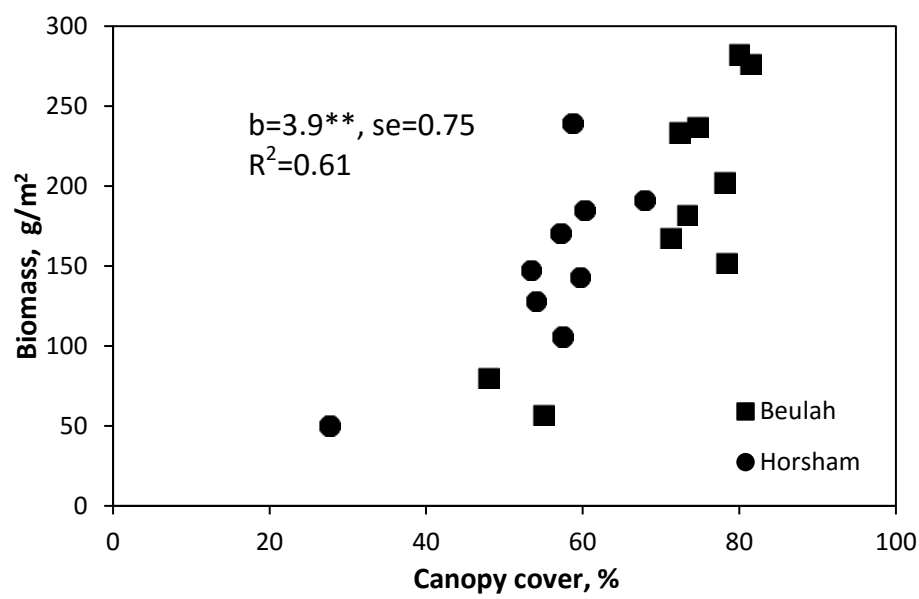

Fig 2. Correlation between canopy cover and biomass at anthesis of juncea canola genotypes at Beulah and Horsham in 2013.* and ** indicate significance at 0.05 and 0.01 level of significance, respectively. 
Table 3. Details of the field experiments conducted from 2012 to 2014.

\begin{tabular}{cccc}
\hline Year & Locations (region) & Juncea canola genotypes & Date of sowing \\
\hline 2012 & Beulah (Mallee) & 19 & 6 June \\
& Piangil (Mallee) & 19 & 14 May \\
& Horsham (Wimmera) & 19 & 7 June \\
2013 & Beulah (Mallee) & 10 & 22 May \\
& Horsham (Wimmera) & 10 & 10 June \\
2014 & Horsham (Wimmera) & 11 & 8 June \\
\hline
\end{tabular}

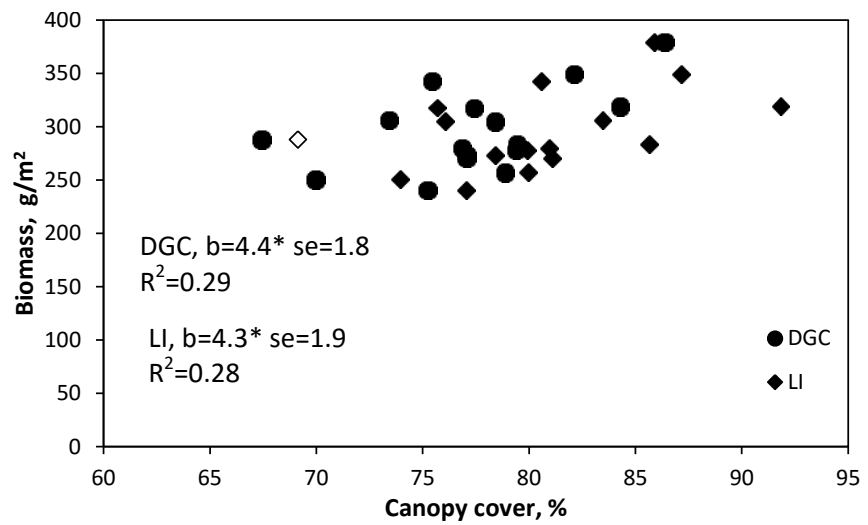

Fig 3. Relationship of biomass at anthesis with indirect methods of canopy cover measurement of juncea canola hybrids at Horsham in 2014. *, significant at 0.05 level; ns, not significant; se, standard error; DGC, digital ground cover; LI, light interception.

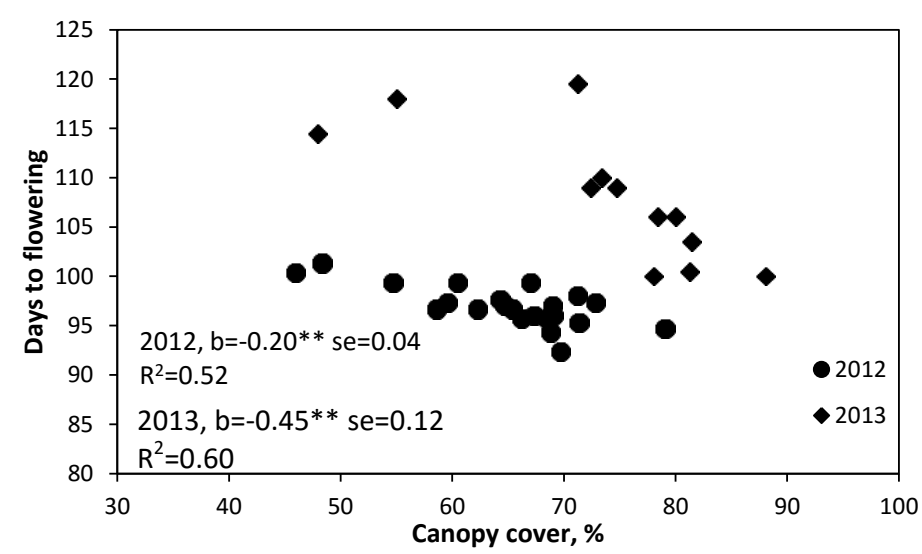

Fig 4. Relationship between canopy cover and days to flowering of juncea canola and canola genotypes at Beulah in 2012 and 2013. $*$ and $* *$ indicate significance at 0.05 and 0.01 level of significance, respectively.

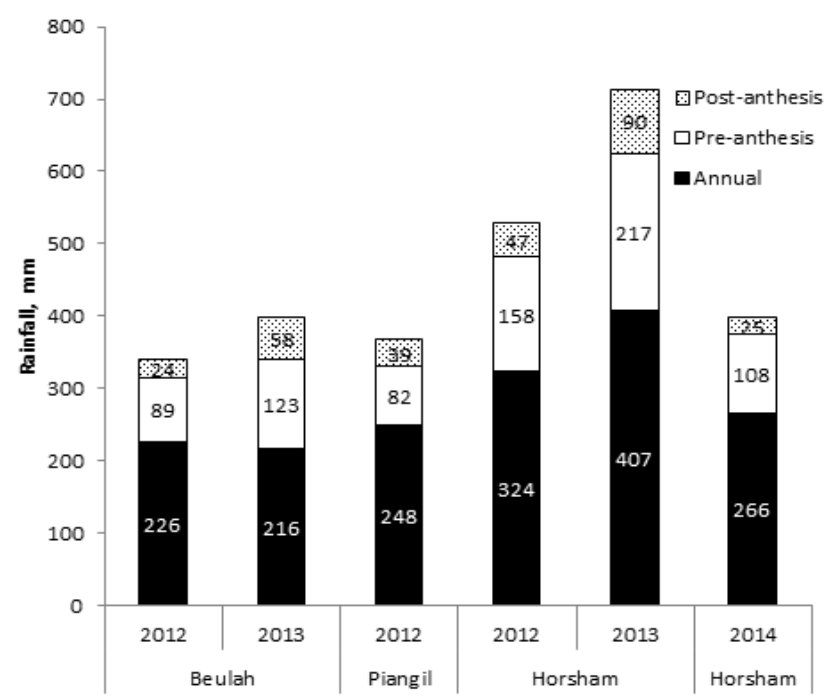

Fig 5. Annual and growing season rainfall before and flowering at experimental sites in different years. Rainfall data were obtained from Australian Government, Bureau of Meteorology website: www.bom.gov.au. 


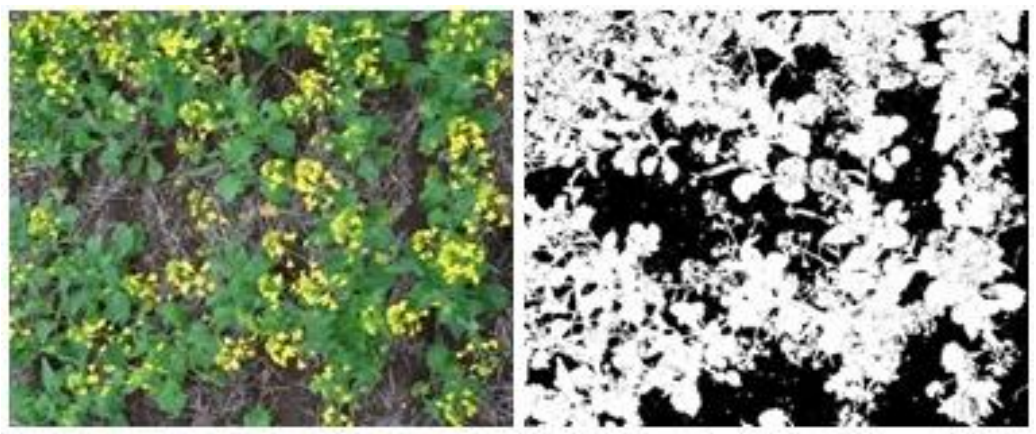

Fig 6. An example of processing of digital photographs with Adobe Photoshop (CS6 Extended version). Original photograph of canopy (left) and photograph after coverting pixels from plant to white and rest to black (right). 'Image Analysis' tool of Adobe Photoshop was used to convert original photograph to white (for pixels from plant) and black (for other colours in background) and to estimate proportion of white pixels of the total pixels in the picture. Above photograph has $59 \%$ digital ground cover.

significantly higher yield than Beulah because of higher postanthesis rainfall. Positive relationships between yield and post-anthesis rainfall have been observed in wheat (Kirkegaard et al., 2007; Passioura, 1977) and in Brassica oilseeds ( $\mathrm{Si}$ and Walton, 2004) under terminal drought conditions. Yield and biomass at anthesis were considerably lower in 2013 at both sites than in 2012 because the sites were affected by heavy rainfall events a few weeks after emergence in 2013. As Horsham was affected more severly than Beulah, biomass and canopy cover at anthesis were significantly lower at Horsham than at Beulah.

Regression analysis found that relationships between biomass at anthesis and canopy cover with seed yield were considerably higher at the low rainfall site (Beulah) than at the relatively higher rainfall site (Horsham) (Table 2). This indicated that the crop vigour at anthesis predicted drought performance of juncea canola hybrids more strongly at relatively low rainfall environments with $<250 \mathrm{~mm}$ annual rainfall. Despite rainfall similar to the Mallee sites, yield was not associated with biomass at anthesis at Horsham in 2014. Horsham is historically a higher rainfall site than sites in the Mallee. Horsham is also known to have more favourable subsoils than the sites in the Mallee. In drier regions like the Mallee, subsoils are often less favourable to root growth because of high salinity, high boron and sodicity. Rodriguez and Nuttall (2003) found that at more than 50\% sites surveyed in the Mallee salinity and sodicity levels were higher than critical values for crop growth below $60 \mathrm{~cm}$ depth. In southern Mallee, wheat yields were affected by subsoil sodicity (Nuttal et al., 2003). Pan et al., (2007) also reported that canopy cover measured with digital photography at vegetative stages could be used to predict seed yield of wheat. A similar relationship was observed in field pea (Munakamwe et al., 2014). In terminal drought conditions, the importance of canopy cover has been demonstrated in many crops. Good canopy cover at anthesis reduces soil evaporation and increases water use efficiency (Blum, 1996; Richards et al., 2001). Biomass from thick stems contributes much less to canopy cover than leaves.

This may be the reason for stronger correlation of seed yield with canopy cover than with biomass production. The indirect methods of canopy cover measurement are nondestructive, easier and demand less time and other resources than the direct biomass sampling. Several researchers have tested the indirect methods of measuring canopy cover (including ceptometer and digital photography) and compared with the LAI by direct sampling in different crops. The indirect measurements gave sufficient accuracy compared with the direct LAI measurement of Kohlrabi and lettuce (Sandmann et al., 2013); wheat (Pan et al., 2007); onion (Corcoles et al., 2013); wheat, maize and sorghum (Armbrust, 1990); and sugar beet (Rover and Koch, 1995). All the studies reported to date on indirect measurement of canopy cover have been focused on replacement of direct sampling for LAI estimation or using other instruments such as LAI-2000 (Nasta et al., 2014). There are no reports on use of these non-destructive canopy cover methods to replace direct biomass sampling or to predict yield performance in Brassica oilseeds.

This study for the first time reports the relationship between indirect methods of canopy cover measurement with biomass sampling and seed yield of juncea canola hybrids. Canopy cover and biomass at anthesis were strongly correlated (Figs 1-3). Canopy cover was measured both as light interception and digital ground cover in 2014. The regression analysis showed that both the measurements had positive relationships with biomass at anthesis and explained similar proportion of variation in biomass at anthesis $(28 \%$ by light interception and $29 \%$ by digital ground cover) (Fig 3). The results suggested that these two methods of canopy cover could be used interchangeably to estimate canopy cover. Chakwizira et al. (2015) also demonstrated that these two measurements could be used to estimate canopy cover of cereals and other crops. The positive linear relationships between seed yield and canopy cover at anthesis were consistently higher than for seed yield against biomass at anthesis. This may be due to partition of more biomass to stem rather than to leaves in high biomass genotypes. Leaves rather than stems are the major plant part contributing to canopy cover. These results indicate that indirect measurement of canopy cover could replace the direct biomass sampling to assess the growth at anthesis and to predict drought performance of juncea canola hybrids. There was a consistent and strong negative significant relationship between number of days to flowering and canopy cover at Beulah (Fig 4). This result indicated that better canopy cover of juncea canola hybrids at anthesis was associated with better adaptation (earlier flowering). Juncea canola is a newly developed crop for low rainfall environments of southern Australia. Open-pollinated cultivars of juncea canola have been released in Australia and hybrid research is under progress. Early vigour with early flowering and quick canopy cover is an important breeding objective of juncea canola breeding in Australia. Current juncea canola germplasm in Australia has sufficient variability in earliness and provides an opportunity to develop germplasm adapted to the low rainfall environments of Australia (Burton et al., 2008). The non-destructive indirect methods of measurement of canopy cover (ceptometer and digital photography) appear useful for repeated and large scale screening of germplasm for early 
vigour, adaptation and yield performance under low yield environments. There was a consistent and positive significant relationship between the indirect methods of canopy cover measurement and direct biomass sampling at anthesis of juncea canola hybrids particularly at low ( $<250 \mathrm{~mm}$ annual) rainfall sites. Furthermore, this report also demonstrates that at low rainfall sites, canopy cover at anthesis predicts yield performance of juncea canola hybrids better than biomass at anthesis.

\section{Materials and Methods}

\section{Experimental details}

Experiments were conducted at two locations (Beulah and Piangil) in the Victorian Mallee and at one location (Horsham) in the Wimmera region in 2012. In 2013 and 2014, the experiments were sown at one location each in the Mallee (Beulah) and the Wimmera (Horsham). However, the experiment failed at Beulah in 2014 because of extreme drought before flowering in the region. All the experiments were laid out in a Randomized Complete Block Design with three replications. Each genotype was planted in a $10 \mathrm{~m}$ long plot with 6 rows (a row spacing of $25 \mathrm{~cm}$ ).

\section{Rainfall at the experimental sites}

Sites in the Mallee region (Beulah and Piangil in 2012 and Beulah in 2013) received less rainfall than in the Wimmera region (Horsham in 2012 and 2013) (Fig 5). The Mallee and Wimmera sites received $<250 \mathrm{~mm}$ and $>250 \mathrm{~mm}$ annual rainfall, respectively. 2013 was a better year in terms of rainfall than the first year (2012) for both Beulah and Horsham. Horsham received considerably less rainfall in 2014 than in 2012 and 2013.

\section{Plant materials}

The field experiments consisted of 19 juncea canola hybrids in 2012; four juncea canola hybrids and six parental lines in 2013; and five juncea canola hybrids and six parental lines in 2014 (Table 3). Each experiment had one juncea canola open-pollinated control cultivar (OasisCL) and 1 to $4 B$. napus control cultivars.

\section{Observations and data analysis}

Biomass at approximately 50\% anthesis was recorded both directly and indirectly. Direct measurement was done by harvesting above-ground biomass from $50 \mathrm{~cm}$ of three rows $\left(3750 \mathrm{~cm}^{2}\right)$. The samples were oven-dried at $70^{\circ} \mathrm{C}$ for at least 72 hours and converted to dry matter per $\mathrm{m}^{2}$. In 2012 , the indirect measurement was carried out using a ceptometer (Sunfleck PAR ceptometer manufactured by Decagon Devices Inc., Pullman, USA) to measure canopy cover. Photosynthetically active radiation (PAR) was measured with the sensor rod at the top of the canopy (approximately $20 \mathrm{~cm}$ above the canopy) and at ground level below the canopy to estimate the proportion of PAR intercepted by the canopy as following:

canopy cover, $\%=\frac{\text { PAR at the top-PAR at the bottom }}{\text { PAR at the top }} \times 100$. Two measurements were taken from each plot and the average value was recorded. In 2013, the indirect measurement was carried out using digital photographs. Two digital photographs of the canopy were taken vertically approximately one metre above the canopy. The images were analysed with Adobe Photoshop (CS6 Extended version) to calculate percent digital ground cover by the canopy as described by Mullan and Garcia (2012) (Fig 6). The 'Image Analysis' tool in the software was used to convert pixels from plant material (e.g. green and yellow) to white and the remainder to black. The proportion of white pixels to total pixels in the picture was estimated as percent digital ground cover. The average ground cover value of the two photographs was recorded for each plot. In 2014, both indirect methods were used to estimate canopy cover. The plots were machine-harvested and plot yields were converted to seed yield per hectare. Number of days from sowing to $50 \%$ flowering was recorded at Beulah and Horsham.

Data were analysed with SAS 9.3 (SAS Institute Inc.). Homogeneity of variance was tested for data from individual sites and across sites using Bartlett's test before conducting ANOVA on pooled data. Mixed ANOVA was used to analyse the effects of genotype, location and interaction of genotype with location and year, considering location and genotype as fixed and replication as random variables. Site means were compared using least significant difference (LSD) at 0.05 level. Linear regressions of seed yield against direct and indirect methods of biomass sampling were studied using REG procedure with SAS 9.3. Relationships between direct and indirect sampling methods, and days to flowering were also studied.

\section{Conclusion}

Canola quality $B$. juncea has been developed for low rainfall environments of Australia and hybrid cultivars are under development to improve yield potential of the crop. Under terminal drought conditions of Australia, better pre-anthesis growth with quick ground cover is an important breeding objective. For the first time, we report a consistent and positive significant relationship between the two methods of indirect canopy cover measurement (light interception with a ceptometer and digital ground cover with digital photography) with direct biomass sampling at anthesis, seed yield and earliness in flowering of juncea canola hybrids under terminal drought conditions of Victoria, Australia. This relationship was more pronounced in environments where annual rainfalls were $<250 \mathrm{~mm}$. The results indicate indirect methods of canopy cover measurement could replace the direct biomass sampling at anthesis. Canopy cover was associated with better adaptation (early flowering) and predicted yield performance of juncea canola hybrids better than biomass sampling in the low rainfall environments.

\section{Acknowledgements}

The study was conducted as a part of $\mathrm{PhD}$ research project (University of Melbourne) at the research sites of Seednet Australia. We are grateful to Seednet Australia for the support with germplasm and all the necessary resources in execution of the research. We thank Steve Barnes and David Hoffmann for their cooperation in conducting trials and data observation. We also thank Dr Allison Gurung for assistance on the manuscript preparation.

\section{References}

Armbrust DV (1990) Rapid measurement of crop canopy cover. Agron J. 82:1170-1171.

Beckie HJ, Johnson EN, Blackshaw RE, Gan Y (2008) Productivity and quality of canola and mustard cultivars under weed competition. Can J Plant Sci. 88:367-372. 
Behrens T, Diepenbrock W (2006) Using digital image analysis to describe canopies of winter oilseed rape (Brassica napus L.) during vegetative developmental stages. J Agron Crop Sci. 192:295-302.

Blum A (1996) Crop responses to drought and the interpretation of adaptation. Plant Growth Regul. 20:135148.

Burton W, Pymer S, Salisbury P, Kirk J, Oram R (1999) Performance of Austrlaian canola quality Brassica juncea breeding lines. Paper presented at the GCIRC 10th international rapeseed congress, Canberra, 26-29 September 1999.

Burton W, Salisbury P, D. M, Plotts D (2007) Dune- the first canola quality $B$. juncea (juncea canola) cultivar and future juncea canola research priorities for Australia. Paper presented at the $15^{\text {th }}$ Australian research assembly on brassicas, Geraldton, Western Australia, 10-14 September 2007.

Burton WA (2009) Juncea canola update. Department of Primary Industries. http://www.australianoilseeds.com/_data/assets/pdf_file/0 019/7354/burton_juncea_canola_2009.pdf.

Burton WA, Flood RF, Norton RM, Field B, Potts DA, Robertson MJ, Salisbury PA (2008) Identification of variability in phenological responses in canola-quality Brassica juncea for utilisation in Australian breeding programs. Aust J Agric Res. 59:874-881.

Chakwizira E, Meenken ED, George MJ, Fletcher AL (2015) Can we use photography to estimate radiation interception by a crop canopy? Plant Biology 17:574-582.

Córcoles JI, Ortega JF, Hernández D, Moreno MA (2013) Use of digital photography from unmanned aerial vehicles for estimation of leaf area index in onion (Allium cepa L.). Eur J Agron. 45:96-104.

Devi KN, Shamurailatpam D, Singh TB, Athokpam HS, Singh NB, Singh NG, Singh LN, Singh AD, Chanu OP, Singh SR, Devi KP, Devi LS (2014) Performance of lentil (Lens culinaris M.) and mustard (Brassica juncea L.) intercropping under rainfed conditions. Aust J Crop Sci. 8:284-289.

Faraji A (2010) Flower formation and pod/flower ratio in canola (Brassica napus L.) affected by assimilates supply around flowering. Int J Plant Prod. 4:271-280.

French RJ, Malik RS, Seymour M (2015) Crop-sequence effects on productivity in a wheat-based cropping system at Wongan Hills, Western Australia. Crop Pasture Sci. 66:580-593.

Gan Y, Malhi SS, Brandt S, Katepa-Mupondwa F, Kutcher HR (2007) Brassica juncea canola in the Northern Great Plains. Agron J. 99:1208-1218.

Guevara-Escobar A, Tellez J, Gonzalez-Sosa E (2005) Use of digital photography for analysis of canopy closure. Agroforest Syst. 65:175-185.

Gunasekera CP, Martin LD, Siddique KHM, Walton GH (2006) Genotype by environment interactions of Indian mustard (Brassica juncea L.) and canola (B. napus L.) in mediterranean-type environments 1 . Crop growth and yield. Eur J Agron. 25:1-12.

Gunasekera CP, French RJ, Martin LD, Siddique KHM (2009) Comparison of the responses of two Indian mustard (Brassica juncea L.) genotypes to post-flowering soil water deficit with the response of canola (B. napus L.) cv. Monty. Crop Pasture Sci. 60:251-261.

Habekotté B (1993) Quantitative analysis of pod formation, seed set and seed filling in winter oilseed rape (Brassica napus L.) under field conditions. Field Crop Res. 35:21-33.
Harries M, Anderson GC, Hüberli D (2015) Crop sequences in Western Australia: what are they and are they sustainable? Findings of a four-year survey. Crop Pasture Sci. 66:634-647.

Haskins B, McCaffery D, Bambach R (2009) Juncea canola in the low rainfall zone of south-western New South Wales. Primefacts 783:1-10.

Hocking PJ, Staper M (2001) Effects of sowing time and nitrogen fertilizer on canola and wheat, and nitrogen fertilizer on Indian mustard. I. dry matter production, grain yield and yield components. Aust J Agric Res. 52:623-634.

Kirkegaard JA, Lilley JM, Howe GN, Graham JM (2007) Impact of subsoil water use on wheat yield. Aust J Agric Res. 58:303-315.

Lee K-J, Lee B-W (2011) Estimating canopy cover from color digital camera image of rice field. J Crop Sci Biotechnol. 14:151-155.

Mahto JL, Haider ZA (2004) Heterosis in Indian mustard (Brassica juncea L. Czern \& Cosson). Journal of Tropical Agriculture 42:39-41.

Malhi SS, Brandt S, Urich D, Lafond GP, Jonston AM, Zentner RR (2007) Comparative nitrogen response and economic evaluation for optimum yield of hybrid and openpollinated canola. Can J Plant Sci. 87:449-460.

Malviya N, Kumar K, Babu U, Verma OP (2012) Heterosis for seed yield, oil content and yield components in Indian mustard (Brassica juncea (L.) Czern and Coss). Plant Archives 12:279-281

McBeath TM, Gupta VVSR, Llewellyn RS, Davoren CW, Whitbread AM (2015) Break-crop effects on wheat production across soils and seasons in a semi-arid environment. Crop Pasture Sci. 66:566-579.

Mullan D, Garcia MB (2012) Crop ground cover. In: Pask A, Pietragalla J, Reynolds M (eds) Physiological breeding II: a field guide to wheat phenotyping. International Maize and Wheat Improvement Centre (CIMMYT), Mexico.

Munakamwe Z, McKenzie BA, Hill GD (2014) The effect of genotype and agronomic factors on crop growth and yield in field peas (Pisum sativum L.) as influenced by radiation interception and utilisation. Aust J Crop Sci. 8:680-688.

Nasta O, Akoumianaki-Ioannidou A, Liakopoulos G, Nikolopoulou AE (2014) Effects of salinity in the form of simulated sea-spray $(\mathrm{NaCl}$ or $\mathrm{NaCl}+\mathrm{H} 3 \mathrm{BO} 3$ solution) on growth and photosynthetic performance of sage (Salvia officinalis). Aust J Crop Sci. 8:1186-1194.

Nuttall JG, Armstrong RD, Connor DJ (2003) Evaluating physicochemical constraints of Calcarosols on wheat yield in the Victorian southern Mallee. Aust J Agric Res. 54:487497.

Oram R, Salisbury PA, Kirk J, Burton W (1999) Brassica juncea breeding In: Salisbury PA (ed) Canola in Australia: the first 30 years, the 10th international rapeseed congress, Canberra, 1999.

Pan G, Li F, Sun G (2007) Digital camera based measurement of crop cover for wheat yield prediction. Paper presented at geoscience and remote sensing symposium, Barcelona, 23-28 July 2007.

Passioura JB (1977) Grain yield, harvest index, and water use of wheat. J Aust Inst Agric Sci. 43:117-120.

Patel CG, Parmar MB, Patel KR, Patel KM (2010) Exploitation of heterosis breeding in Indian mustard, Brassica juncea (L.) Czern \& Coss. J Oilseeds Res. 27:4748.

Pradhan AK, Sodhi YS, Mukhopadhyay A, Pental D (1993) Heterosis breeding in Indian mustard (Brassica juncea L. Czern \&amp; Coss): analysis of component characters contributing to heterosis for yield. Euphytica 69:219-229. 
Rakow G, Raney JP, Males D (1995) Field performance of canola quality Brassica juncea. In: Murphy D (ed) GCIRC 9th international rapeseed congress, Cambridge, 1995.

Richards RA, Condon AG, Rebetzke GJ (2001) Traits to improve yield in dry environments. In: Reynolds MP, Ortiz-Monasterio JI, McNab A (eds) Application of wheat physiology in wheat breeding. Imternational Maize and Wheat Improvement Centre (CIMMYT), Mexico.

Richardson MD, Karcher DE, Purcell LC (2001) Quantifying turfgrass cover using digital image analysis. Crop Sci. 41:1884-1888.

Robertson MJ, Holland JF, Cawley S, Potter TD, Burton W, Walton GH, Thomas G (2002) Environmental and genotypic control of time to flowering in canola and Indian mustard. Aust J Agric Res. 53:793-809.

Rodriguez D, Nuttall J (2003) Adaptation of the APSIMwheat module to simulate the growth and prodution of wheat on hostile soils. Paper presented at the XI Australian agronomy conference, Geelong, 2-5 February 2013.

Röver A, Koch HJ (1995) Indirect determination of leaf area index of sugar beet canopies in comparison to direct measurement. J Agron Crop Sci. 174:189-195.
Sandmann M, Graefe J, Feller C (2013) Optical methods for the non-destructive estimation of leaf area index in kohlrabi and lettuce. Sci Hortic. 156:113-120.

Si P, Walton GH (2004) Determinants of oil concentration and seed yield in canola and Indian mustard in the lower rainfall areas of Western Australia. Aust J Agric Res. 55:367-377.

Taylor AJ, Smith CJ (1992) Effect of sowing date and seeding rate on yield and yield components of irrigated canola (Brassica napus L.) grown on a red-brown earh in south-eastern Australia. Aust J Agric Res. 43:1629-1641.

Tommey AM, Evans EJ (1992) The influence of pre-floral growth and development on the pathway of floral development, dry matter distriution and seed yield in oilseed rape (Brassica napus L). Ann Appl Biol. 121:687696

Yasari E, Patwardhan AM, Ghole VS, Omid GC, Ahmad A (2008) Relationship of growth parameters and nutrient uptake with canola (Brassica napus L.) yield and yield contribution at different nutrients availability. Pak J of Biol Sci. 11:845-853. 